\title{
A FORMAÇÃO DO PROFESSOR PARA O ENSINO SUPERIOR: APONTAMENTOS SOBRE O ESTÁGIO DOCENTE
}

\author{
TEACHER TRAINING FOR UNIVERSITARY TEACHING: \\ NOTES ON THE TEACHING INTERNSHIP
}

\section{EL ENTRENAMIENTO DEL PROFESOR PARA UNA ENSEÑANZA SUPERIOR: APUNTAMIENTOS SOBRE LA PASANTÍA DOCENTE}

\author{
Antonio Escandiel de Souza ${ }^{1}$ \\ https://orcid.org/0000-0001-6531-3794 \\ Larissa Beck Gardin ${ }^{2}$ \\ https://orcid.org/0000-0002-6050-1857 \\ Sirlei de Lourdes Lauxen ${ }^{3}$ \\ https://orcid.org/0000-0002-8260-0039

\footnotetext{
${ }^{1}$ Universidade de Cruz Alta, Cruz Alta, Rio Grande do Sul - Brasil. E-mail: asouza@unicruz.edu.br.

2 Universidade de Cruz Alta, Cruz Alta, Rio Grande do Sul - Brasil. E-mail: larissabeckgardin@hotmail.com.

${ }^{3}$ Universidade de Cruz Alta, Cruz Alta, Rio Grande do Sul - Brasil. E-mail: s.lauxen@unicruz.edu.br.
}

\section{Resumo}

Este artigo tem como propósito promover uma reflexão sobre a formação do professor universitário, bem como discutir o papel dos programas stricto sensu na formação docente. Para tanto, traz o relato do estágio docente realizado por uma mestranda de uma universidade comunitária do Rio Grande do Sul, estágio este que fez parte da disciplina de Docência no Ensino Superior e objetiva atender ao que destaca a Coordenação de Aperfeiçoamento de Pessoal de Nível Superior (CAPES) ao afirmar que cabe aos programas de pós-graduação, mestrado e doutorado a formação para o exercício do magistério superior. Busca-se descrever e refletir sobre os caminhos percorridos no desenvolvimento da práxis que se realizou no curso de Pedagogia a partir de um estudo de cunho qualitativo dos documentos institucionais (Plano de Desenvolvimento Institucional [PDI] e Projeto Pedagógico dos Curso [PPC]). A experiência possibilitou a reflexão sobre a relação entre teoria e prática no ensino superior, proporcionando à mestranda um crescimento importante na trajetória da formação para o exercício da docência no ensino superior. A atividade possibilitou a constatação de que a 
prática docente universitária exige comprometimento e compreensão da docência como possibilidade de intervenção no mundo.

Palavras-chave: Prática Docente. Professor Universitário. Teoria e Prática.

\begin{abstract}
This article aims to promote a reflection on the training of university professors, as well as to discuss about and the role of stricto sensu programs in teacher training. Therefore, it brings the report of the teaching internship carried out by a master's student at a community university in Rio Grande do Sul, an internship that was part of the teaching discipline in higher education and aims to meet what highlights Coordenação de Aperfeiçoamento de Pessoal de Nivel Superior (CAPES) when stating that it is up to the graduate, masters and doctorate education programsto train for the exercise of higher education. It seeks to describe and reflect on the paths taken in the development of praxis, which took place in the Pedagogy course, based on a qualitative study in institutional documents (Plano de Desenvolvimento Institucional [PDI] e Projeto Pedagógico dos Curso [PPC]). The experience enabled reflection on the relationship between theory and practice in higher education, providing the masters student with an important growth in the trajectory of training for the exercise of teaching in higher education. The practice enabled the realization that the university teaching practice requires commitment and understanding of teaching as a possibility of intervention in the world.
\end{abstract}

Keywords: Teaching Practice. College Professor. Theory and Practice.

\title{
Resumen
}

Este artículo tiene como objetivo promover una reflexión acerca del entrenamiento del profesor universitario, así como discutir el papel de los programas stricto sensu en el entrenamiento docente. Para eso trae el informe de la pasantía docente realizada por una estudiante de maestría en una universidad comunitaria en Rio Grande do Sul, una pasantía que formó parte de la disciplina de Docencia en la Enseñanza Superior y tiene como objetivo cumplir con lo que destaca la Coordenação de Aperfeiçoamento de Pessoal de Nível Superior (CAPES) al afirmar que cabe a los programas de posgrado, maestría y doctorado el entrenamiento para el ejercicio del magisterio superior. Se busca describir y reflexionar sobre los caminos tomados en el desarrollo de la praxis que se ha realizado en el curso de Pedagogía desde un estudio cualitativo de documentos institucionales (Plano de Desenvolvimento Institucional [PDI] e Projeto Pedagógico dos Curso [PPC]). La experiencia permitió reflexionar sobre la relación entre teoría y práctica en la enseñanza superior, proporcionando a la estudiante de maestría un importante crecimiento en la trayectoria de entrenamiento para el ejercicio de la docencia en la enseñanza superior. La actividad permitió comprenderse que la práctica docente universitaria exige compromiso y comprensión de la docencia como posibilidad de intervención en el mundo.

Palabras clave: Práctica Docente. Profesor Universitario. Teoría y Práctica. 


\section{Introdução}

O presente artigo tem como propósito promover uma reflexão sobre a importância da formação do docente no ensino superior, bem como discutir o papel dos programas stricto sensu na formação docente. Para tanto apresenta uma prática de estágio docente realizada no curso de Pedagogia de uma universidade comunitária do Rio Grande do Sul.

Em termos metodológicos, a pesquisa orientou-se pela abordagem qualitativa, a partir do estudo de documentos institucionais, entre os quais o Plano de Desenvolvimento Institucional (PDI) da universidade e o Projeto Pedagógico dos Curso (PPC), das observações das aulas ministradas pela professora titular e da experiência em sala de aula com uma turma do curso de Pedagogia. Nesse sentido, o texto destaca, ainda, a importância da formação docente com base em autores como Freire (2011), Domingo (2002), Rossato (2002) e Soares e Cunha (2010), entre outros.

Vale destacar que, cada vez mais, os desafios contemporâneos exigem da profissão docente mudanças e melhorias na sua prática educativa, tanto nas dimensões pessoal e social, quanto na dimensão pedagógica. Por esse motivo, compreende-se como necessária a discussão sobre a docência pelo fato de o professor ser um ator social com um importante papel na formação de sujeitos críticos capazes de colaborar para a melhoria da sociedade em que vivem.

A preocupação com a prática pedagógica nem sempre foi o foco da pós-graduação stricto sensu, pois, a partir da criação da pós-graduação pela Coordenação de Aperfeiçoamento de Pessoal de Nível Superior (CAPES), em 1970, a ênfase era, prioritariamente, a pesquisa.

É muito importante conhecermos a trajetória do ensino superior em nosso país, mas, sobretudo, é necessário destacarmos que a preocupação com a educação e a profissionalização é um debate recente na sociedade brasileira. Nesse sentido, Rossato (2002) argumenta que por muito tempo a busca pela formação era reconhecida como iniciativa individual ou de pequenos grupos, pois, até a independência do Brasil, os "letrados" não passavam de $0,5 \%$ da população, tendo ocorrido um verdadeiro processo de constituição do sistema de educação nacional apenas a partir do século XX.

Em tempos atuais, o autor supracitado sugere que o significado de "ser professor" passa, primeiramente, pelo entendimento de "quem é o homem?", e, a partir de então, 
compreende-se o que é educação. E, refletindo sobre o "ser homem - humano", Rossato (2002), a partir de exposições subjetivas sobre a composição desse sujeito, conclui que "não somos feitos para coisas pequenas: somos seres de desejo, insaciáveis, buscando permanentemente novas conquistas" (p. 92). Ele relaciona isso com a melhor compreensão sobre a educação, a análise do conhecimento que devemos buscar e qual educação queremos.

Elaborando um mosaico de conhecimentos e reflexões sobre a importância da educação na constituição de uma nação, este artigo busca mostrar a relevância da formação para a docência e a importância do estágio de docência, tendo em vista a função social que exerce o professor do ensino superior na formação dos sujeitos, proporcionando, a partir de sua visão de homem e de mundo, a ampliação da capacidade crítica e reflexiva de cada cidadão.

\section{A docência no ensino superior}

Torna-se pertinente compreender o papel dos programas stricto sensu na formação docente, iniciando com as considerações sobre a docência no ensino superior a partir do que preconiza a Lei de Diretrizes e Bases da Educação n 9.394/96 (LDB), em seu artigo 66, o qual argumenta que "a preparação para o exercício do magistério superior far-se-á em nível de pós-graduação, prioritariamente em programas de mestrado e doutorado" (BRASIL, 1996, p. 72).

São de responsabilidade desses programas a organização e a condução do processo de formação, e não haverá, consoante o artigo, uma intervenção da legislação no processo. Essa "liberdade" concedida aos programas stricto sensu reflete, no entanto, a pouca preocupação com a necessidade de formação docente para o ensino superior. É possível fazer-se essa afirmação ao se estabelecer a comparação com o artigo 65 da LDB, que determina que "a formação docente, exceto para a educação superior, incluirá práticas de ensino de, no mínimo, trezentas horas" (BRASIL, 1996, p. 72).

Sobre essa questão, salienta-se, nas políticas públicas, a não exigência de uma formação para professores de educação superior que contemple os saberes específicos da docência, como os relacionados com os processos de ensino e aprendizagem, incluindo a avaliação e o planejamento, enfim, a condução da aula em suas múltiplas possibilidades (SOARES; CUNHA, 2010). 
Apesar de ser um tema complexo, é muito importante que se reflita sobre a qualificação para a docência no ensino superior, pois a pós-graduação stricto sensu normalmente privilegia a formação para a pesquisa, em vez de se preocupar também com a questão pedagógica.

Ao se manifestarem sobre isso, Soares e Cunha (2010) escrevem que os programas de stricto sensu preferem a formação para a pesquisa e que, por isso, parecem ter assumido a concepção de que os saberes de investigação são suficientes ou se transformam automaticamente em saberes de docência, reconhecendo a formação do docente universitário como consequência natural da formação do pesquisador.

As autoras fazem essa afirmação com base em um estudo realizado com professorespesquisadores e coordenadores de dois cursos distintos de mestrado e doutorado. A partir da análise dos programas lócus da pesquisa, Soares e Cunha (2010) constataram a predominância da pesquisa em comparação com o ensino, evidenciando, entre os resultados, que o professor universitário deve ter competências para fazer pesquisa. Essa constatação é ilustrada pelas autoras por meio da fala de um dos professores entrevistados, o qual menciona que "[...] a pesquisa é produção, o ensino é basicamente transmissão" (SOARES; CUNHA, 2010, p. 589).

O professor do contexto universitário, nesse sentido, constrói a sua identidade docente com base nas vivências familiares, de modelos de antigos professores, a partir da troca entre os colegas e entre os professores mais experientes da área (SOARES e CUNHA, 2010). E esse fato demonstra que os programas de mestrado e doutorado estão realmente priorizando a formação de pesquisadores, deixando em segundo plano a formação para a docência universitária.

Como a formação de professores universitários, embora seja uma discussão recorrente por muitos autores da área da Educação, tem ficado em segundo plano no âmbito da pósgraduação stricto sensu, Cunha (2009) ressalta a necessidade de constantes reflexões e análise das práticas e conhecimentos construídos. A autora afirma que se trata de um processo que requer constantes interações e mudanças que envolvem os partícipes. Nesse sentido, as sugestões ou orientações do professor titular ao estagiário, por exemplo, podem resultar em novas ações resultantes desse processo crítico-reflexivo. 
Pensar o papel do docente no ensino superior requer o entendimento de um processo de atuação voltado à execução de ações com vistas ao alcance de resultados previstos. É necessário, para tanto, resgatar a base reflexiva da atuação profissional como forma de entender as dificuldades da prática e reinventar intervenções pedagógicas que propiciem autonomia e pensamento crítico.

Nesse sentido, para que um professor incentive a criticidade, o docente do ensino superior precisa desenvolver sua própria capacidade reflexiva, pois onde não há reflexão do papel docente encontramos apenas o cumprimento de regras para a obtenção de resultados específicos.

Contreras (2002) destaca que, quando as regras técnicas não são suficientes na atuação profissional, faz-se necessário o desenvolvimento das habilidades humanas diretamente relacionadas com a capacidade de deliberação, a reflexão e a consciência, fornecendo atributos que objetivam entender e encontrar a melhor forma de abordar as situações problemáticas da prática.

Ao refletir sobre docência a partir dos estudos de Schön (1992), Contreras (2002) compreende que ser um profissional reflexivo proporcionará uma atuação distinta frente a situações incertas, instáveis e singulares em que estão presentes conflitos de valor.

Contreras (2002) ressalta a importância da distinção entre "conhecimento na ação" e "reflexão na ação". O conhecimento na ação se dá nas atividades habituais em que está presente um conhecimento implícito, sobre o qual não exercemos controle, pois ocorre de forma que não nos damos conta conscientemente do aprendizado. Nesse momento, o conhecimento não antecede a ação, ele está na ação.

Já a reflexão na ação ocorre, geralmente, em situações que fogem ao que é corriqueiro, quando somos surpreendidos, obrigando-nos a pensar sobre o que estamos fazendo. Pressupõe refletirmos sobre a ação realizada habitualmente frente à situação vivenciada no momento.

A reflexão na ação, quando exercida diuturnamente, resulta na adoção de características específicas para o exercício da prática docente. A reflexão leva o profissional a elaborar um conjunto de técnicas que servirão para a tomada de decisões ante fatos imprevistos, e a experiência é que alimenta seu conhecimento na prática (CONTRERAS, 2002). 
A experiência gera mais confiança para a resolução de problemas. Para cada nova situação inesperada e diferente das já vividas, é preciso uma nova reflexão na ação, construindo um movimento em espiral: ação - reflexão - nova ação - nova reflexão. Toda nova ação reflexiva é demandada por problemas para os quais já não são mais válidas as resoluções conhecidas pelos profissionais em seu repertório de casos, sendo fundamental o reconhecimento de que cada docente, no papel reflexivo, deve adotar essa atitude, compreendendo que é parte integrante da situação a ser resolvida.

Contreras (2002) menciona ainda que a construção da dimensão reflexiva na prática docente dá legitimidade a uma nova forma de entendermos e apresentarmos uma atuação racional não técnica, mas, sim, artística, conectando o conhecimento e a ação em contextos práticos. O autor convida todos a olhar para a educação sob os holofotes da arte e nos apresenta o estudo de Stenhouse, que, ao tratar do profissional reflexivo, disserta sobre o "professor como pesquisador" e compara a educação com a arte.

Para Stenhouse, o ensino é uma arte, visto que significa a expressão de certos valores e de determinada busca que se realiza na própria prática do ensino. Por isso, pensa que os docentes são como artistas, que melhoram sua arte experimentando-a e examinando-a criticamente. (CONTRERAS, 2002, pág.114)

O autor continua suas reflexões afirmando que tanto Schön quanto Stenhouse expressam suas posições sobre os professores apontando para uma resistência aos modelos de racionalidade técnica. Schön (2000) destaca a prática reflexiva opondo a lógica de profissional especialista ou técnico. Já Stenhouse (1981) critica o modelo de objetivos curriculares que reduz o potencial de consciência profissional e, por consequência, sua potencialidade de pretensão educativa, sendo necessário romper com o que está posto e olhar para a singularidade das situações educativas.

Outro aspecto importante refere-se à introdução do termo "saberes" na literatura pedagógica. O termo, segundo Cunha (2010), surge para identificar pensamentos, ideias, juízos, discursos e argumentos ligados a determinadas exigências de racionalidades.

Os "saberes" fundamentarão a consciência dos atos exercidos, dando racionalidade ao sujeito que justificará suas ações com base em razões, procedimentos ou discursos. As razões ou justificativas que movem a atuação docente muitas vezes têm sua base em questões 
subjetivas ou históricas, que nem sempre se firmam na cientificidade do conhecimento, embora devam ser observadas a partir de racionalidades integrantes do exercício docente. Por isso diz-se que os saberes são heterogêneos e constituídos de múltiplas origens.

Mas quais saberes devem fazer parte do cotidiano do fazer docente? Cunha (2010) apresenta, em seus estudos, a organização de saberes definindo-os a partir de diferentes critérios de agrupamento e o faz com o objetivo de fortalecer a capacidade de reflexão do professor para que este possa atuar com argumentos racionais característicos de quem tem certeza de suas ações.

Neste sentido, teremos, portanto, para a realização de um trabalho qualificado e responsável, a possibilidade de constituir grupos de saberes para o fortalecimento da atuação profissional estudados e propostos por Cunha (2010).

A autora refere-se aos saberes relacionados com o contexto da prática pedagógica, ressaltando que é fundamental o conhecimento do espaço escolar, identificando as questões sociais e culturais que constituem o ambiente em que se processarão o ensino e a aprendizagem.

Quanto aos saberes referentes à dimensão relacional e coletiva das situações de trabalho e dos processos de formação, a autora escreve que esses caracterizarão a atividade socioeducativa do professor. Esses saberes são, segundo Cunha (2010), a capacidade de estabelecimento de parcerias, descaracterizando a lógica da educação como uma questão individual para uma visão de formação que surge de processos coletivos.

Os saberes relacionados com a ambiência da aprendizagem articulam conhecimento e prática social, são a forma como se incentiva a curiosidade do aluno e o envolvimento com a proposta de ensino, conhecendo as condições de aprendizagem e as possibilidades de evolução (CUNHA, 2010).

Já os saberes relacionados com o contexto sócio-histórico dos alunos referem-se à capacidade de conhecimento e reconhecimento das condições sociais e culturais dos alunos. São o estímulo à capacidade discursiva a partir de memórias educativas, promovendo o conhecimento de forma autobiográfica. São o desenvolvimento do ensinar e aprender conectado socialmente, fortalecendo, assim, o desenvolvimento da cidadania. 
Métodos utilizados, tempo disponível, condição dos alunos e metas a serem conquistadas. Tais saberes indicam um domínio do que se ensina e, conforme o autor, auxiliarão na composição dos objetivos de aprendizagem.

Os saberes se relacionam com a condução da aula nas suas múltiplas possibilidades. Cunha (2010) afirma que dispor desses saberes indicará a capacidade do professor de agir como um artesão na elaboração de aprendizagens significativas, baseadas em estruturas culturais, afetivas e cognitivas. Constituirá um arcabouço de técnicas e procedimentos de ensino e a escolha de recursos apropriados.

As estratégias para melhor identificar e informar sobre a aprendizagem do estudante exigem conhecimento técnico e sensibilidade pedagógica e referem-se aos saberes relacionados com a avaliação da aprendizagem.

Cunha (2010), ao estabelecer o agrupamento desses saberes, sugere, ainda, a articulação da multiplicidade de conhecimentos necessários para o desenvolvimento da docência em toda sua complexidade. Diante dessas reflexões, percebemos que o fazer docente requer dedicação e rigor metodológico, sobretudo quando se pretende ser e formar profissionais reflexivos, características essenciais à docência universitária.

\section{O estágio docente: caminhos percorridos no desenvolvimento da práxis}

Ao refletir sobre a prática realizada, vale destacar que o estágio docente descrito fez parte da disciplina de Docência no Ensino Superior, oferecida pelo mestrado de uma universidade comunitária do Rio Grande do Sul, cujo nome será preservado. O estágio docente na graduação é um requisito parcial para aprovação na referida disciplina, a qual tem uma carga horária de 60 horas distribuídas em 30 horas para discussões teóricas e orientações para o estágio a ser realizado em curso de graduação e 30 horas para a prática em sala de aula. Esse estágio oferecido pela disciplina tem como finalidade possibilitar ao estagiário o contato com o ambiente profissional, proporcionando-lhe a construção do conhecimento teóricoprático, que só se torna possível quando ele está inserido no contexto da sala de aula.

O estágio docente oferecido por essa universidade atende ao que destaca a CAPES ao afirmar que cabe aos programas de pós-graduação, mestrado e doutorado a formação para o 
exercício do magistério superior. O estágio de docência no ensino superior é parte integrante da formação do pós-graduando, objetivando a preparação para a docência e a qualificação do ensino de graduação, sendo obrigatório para todos os bolsistas do Programa de Demanda Social (CAPES, 2010, p. 31).

Trata-se de uma prática que se constitui como uma importante oportunidade de que o pós-graduando dispõe para ter uma primeira experiência docente no ensino superior e estabelecer a relação teoria e prática no que se refere ao processo de ensino e aprendizagem.

O estágio docente prevê, conforme o artigo $6^{\circ}$ do Regulamento de Estágio da disciplina de Docência no Ensino Superior, as seguintes atribuições ao discente do PPG:

I. Elaborar o plano de atividades em conjunto com o professor da graduação;

II. Desenvolver com ética e responsabilidade as atividades previstas no plano aprovado;

III. Entregar relatório final do estágio ao supervisor da disciplina de Docência no Ensino Superior, para fins de homologação de créditos e registro no histórico escolar.

A prática de estágio docente universitário que ora descrevo e reflito constituiu-se de 30 horas-aula, distribuídas em 18 horas para observações, análise dos documentos institucionais e planejamento das aulas e 12 horas destinadas à prática. $\mathrm{O}$ estágio foi realizado no curso de Pedagogia, modalidade Plano Nacional de Formação de Professores da Educação Básica (PARFOR).

O contexto da experiência prática foi uma turma do $4^{\circ}$ semestre, na disciplina de Educação, Diversidade e Inclusão, cujo objetivo é fornecer subsídios para a docência inclusiva, potencializando professores para que estejam aptos a valorizar a multiplicidade e as diferenças individuais, atuando em contextos diversos. A disciplina trabalha as possibilidades de compreensão da trajetória da educação especial e busca promover reflexões sobre a formação do professor para a docência inclusiva, estimulando a visão crítico-reflexiva do acadêmico.

Convém destacar, inicialmente, que a experiência de estágio, o acompanhamento, o auxílio e a mediação de aulas possibilitaram-me a construção/aproximação das questões epistemológicas da disciplina, o que permitiu a constatação da importância de desenvolver 
uma metodologia de ensino que permita ao discente uma participação ativa e crítica no processo de aprendizagem.

Para a fundamentação adequada e o planejamento da atuação docente, é necessário compreender os objetivos da instituição de ensino e sua missão ante a sociedade em que está inserida. Nesse sentido, realizou-se a leitura do Plano de Desenvolvimento Institucional (PDI) da instituição de ensino superior (IES), bem como do Projeto Pedagógico do Curso (PPC), a fim de conhecer a proposta da instituição e do curso de Pedagogia. Essa leitura é essencial, pois o planejamento e a prática docente universitária devem estar sempre em consonância com essa documentação institucional. Pimenta e Anastasiou (2011) ressaltam a importância de o docente ter o conhecimento do sistema da instituição onde está exercendo sua profissão, principalmente os objetivos institucionais, os princípios teóricos e metodológicos e o perfil do egresso de cada curso.

As observações para conhecimento prévio das características da turma em que o estágio seria realizado possibilitaram-me a constatação de uma conexão entre a proposta da instituição e do curso no que se refere ao perfil do profissional a ser formado. O plano de ensino elaborado pela professora titular da turma para o semestre evidenciou convergência com a missão da universidade e os objetivos fundamentais para a formação de pedagogos. Sobre isso vale destacar que a leitura e análise dos documentos institucionais foram fundamentais para o planejamento das aulas, pois a partir delas pude identificar o perfil do pedagogo que a universidade pretende formar. Aliás, ao refletir sobre o planejamento da professora da turma, constatei que há, de fato, bastante preocupação em exercer a docência conforme esses documentos. Inclusive constam, no plano de ensino, palavras do PDI da universidade.

Foi visível, na condução das aulas por parte da professora titular, a presença de espaço para o desenvolvimento da capacidade crítico-reflexiva, de acordo com a realidade de cada acadêmico. E, nesse sentido, o planejamento das leituras, discussões e avaliações que foram sempre realizadas de acordo com os objetivos da disciplina e as atividades de sala de aula ocorreram por meio de metodologias variadas, possibilitando a criatividade e respeitando a singularidade do grupo de alunos.

A oportunidade do estágio proporcionou-me, portanto, o conhecimento do perfil de pedagogo que a instituição deseja formar para que ele, inserido em diferentes contextos, seja 
capaz de promover a transformação social. Entre várias características a serem desenvolvidas na formação do profissional em Pedagogia, destacamos o trabalho para o desenvolvimento de habilidades capazes de formar um "profissional inovador, criativo, prospectivo, pesquisador, investigativo, capaz de lidar com as diferentes situações que se apresentam" (PDI, 20182022).

As potencialidades a serem desenvolvidas pela formação no curso de Pedagogia e a atuação da professora titular da disciplina demonstraram que a missão da referida universidade está presente na prática, pois a docente desenvolveu atividades planejadas para obter a produção e socialização de conhecimento qualificado, contribuindo para a "formação de cidadãos críticos, éticos e comprometidos [...]" (PDI, 2018-2022).

O fato de não ter formação em Pedagogia exigiu-me leituras prévias da bibliografia utilizada na disciplina, a fim de tornar-me apta a discutir e propor, com segurança, novas propostas metodológicas. Nesse sentido, Cunha (2009) destaca que alternativas emancipatórias necessitam de conhecimentos teóricos e competência prática que transcendam um saber-fazer por muito tempo dirigido a um processo de reprodução do conhecimento.

Durante o estágio, foram realizadas atividades como seminários e discussões sobre vídeos que abordavam a temática das aulas. As ações tinham como propósito promover a construção do conhecimento por meio do diálogo entre docente e discentes. Os discentes tiveram a oportunidade de se manifestar, opinando e estabelecendo relação entre a teoria discutida e a prática de sala de aula.

Com base em Freire (2011), é possível pontuar que a vivência reflete a importância do estudo para o domínio do tema a ser trabalhado nas aulas. Pela competência profissional, pelo estudo e pelo domínio do tema é que cada professor poderá exercer sua função com autoridade e segurança. É importante salientar que Freire fala de autoridade oriunda do sentimento de segurança gerado pelo aprofundamento teórico e rigor metodológico de cada professor. Não se refere ao exercício da autoridade vinculado ao significado de autoritarismo. O comprometimento e a seriedade são fundamentais ao fazer docente, pois o professor que não leva a sério sua formação, que não estuda, que não se esforça para estar à altura de sua tarefa não tem força moral para coordenar as atividades de sua classe (FREIRE, 2011).

Para a obtenção de tal segurança na condução das aulas, além das leituras prévias que permitiram o aprofundamento teórico sugerido por Freire (2011), realizei o planejamento 
conjunto com a professora titular da disciplina, estabelecendo o diálogo necessário ao sucesso das atividades.

Retomando a reflexão sobre a complexidade de saberes que envolvem a atuação docente, ao desenvolvermos as aulas, que tiveram como tema a inclusão de pessoas com deficiência e as possibilidades de trabalho pelo viés da escola inclusiva, percebemos o quanto as questões individuais de reconhecimento da visão de homem e de mundo e as questões sociais externas e estruturais de trabalho de cada acadêmico do curso de pedagogia PARFOR têm interferido na formação e na prática profissional de cada um.

Percebi que, ao pensar nas possibilidades pedagógicas para a efetividade da proposta inclusiva nas escolas, automaticamente as alunas da graduação traziam para o debate as barreiras existentes no cotidiano, fortalecendo, a cada posicionamento, a sensação de distanciamento entre a teoria e a realidade vivida.

Nesse sentido, foi um desafio abordar a temática, respeitando e valorizando a realidade vivida pelas estudantes e, ao mesmo tempo, foi estimulante motivá-las a observar aspectos positivos na responsabilidade assumida por cada uma ao buscar a qualificação profissional, incentivando-as a utilizar o conhecimento adquirido para a efetividade do ensino e da aprendizagem e para a garantia de acesso à educação especializada, previstas legalmente para as crianças e adolescentes com algum tipo de deficiência.

Compreender as especificidades de cada sujeito e desenvolver o papel de docente com autoridade, mas, especialmente, com liberdade, torna essa relação mais ética, pois, conforme Freire (2011), o educando que exercita sua liberdade ficará tão mais livre quanto mais eticamente vá assumindo a responsabilidade de suas ações.

O estágio docente constituiu, para mim, um grande desafio, um momento de enriquecimento epistemológico e profissional. Uma experiência extremamente importante, ainda que permeada por conflitos, dúvidas e muitas expectativas; entretanto, à medida que as aulas foram acontecendo, as dúvidas e angústias, com o auxílio da professora titular e dos docentes da disciplina de Docência no Ensino Superior, no mestrado, transformaram-se em segurança e prazer. Foi uma experiência muito interessante, pois, como sou assistente social, realizar estágio docente em uma turma do curso de Pedagogia configurou-se um grande desafio. Confesso que, no início, senti um certo receio, mas a professora da disciplina da graduação e os docentes orientadores de estágio do mestrado me auxiliaram e conseguiram 
me fazer sentir mais segura. Foi uma prática que exigiu muita leitura para que eu entrasse em sala de aula preparada para conduzir as discussões com segurança e respaldo teórico.

A experiência de estágio no ensino superior proporcionou um crescimento importante na trajetória da formação docente pretendida. Observar na prática a dedicação necessária para pôr em prática as discussões e teorias estudadas na disciplina de Docência no Ensino Superior, percebendo a responsabilidade do ser docente na vida dos sujeitos que buscam crescimento pessoal e profissional, certamente deixa marcas que refletirão na caminhada que vem sendo construída em meu processo de qualificação na pós-graduação stricto sensu.

O processo de formação pedagógica do professor do ensino superior é bastante desafiador e nada garante que o processo formativo assegure o sucesso do docente na sala de aula, entretanto a formação pedagógica que alia a teoria à prática possibilita a reflexão e a consciência acerca da docência, compreensões essenciais ao exercício da profissão. Nesse sentido, este relato de estágio tem como propósito fomentar a reflexão acerca da relevância do "pensar a docência" no contexto da pós-graduação stricto sensu. Para isso, concordamos com Pimenta e Anastasiou (2011, p. 109) quando reforçam "que a docência universitária é profissão que tem por natureza constituir um processo mediador entre sujeitos essencialmente diferentes, professores e alunos, no confronto e na conquista do conhecimento".

Como o conhecimento científico não significa, necessariamente, qualificação para o exercício docente no ensino superior, o processo de formação pedagógica e formação para a pesquisa devem andar juntos, o que pode garantir uma formação profissional mais completa.

\section{Considerações finais}

Encerramos as breves reflexões apresentadas neste texto sobre o papel dos programas stricto sensu na formação docente considerando que, ainda hoje, a pós-graduação stricto sensu tem como objetivo central formar pesquisadores. Isso faz que os mestrandos e doutorandos envolvam-se muito na obtenção de dados de pesquisa que garantam teses e dissertações com a qualidade necessária para assegurar sua publicação em periódicos científicos qualificados. Após a conclusão dos seus cursos, no entanto, os mestres e doutores brasileiros, em sua maioria, passam a atuar em instituições de ensino superior, proporção que, segundo os dados do Plano Nacional de Pós-Graduação, chega a 66\% (BRASIL, 2010). Por 
isso a importância de os programas oferecerem disciplinas de docência e estágios de docência na educação superior.

Vale destacar, a partir da vivência da prática docente, que a docência como profissão requer do profissional não somente o domínio do conhecimento necessário à sua prática, mas também a constante transformação desses conhecimentos, haja vista que o processo de aprendizagem constitui uma troca, pois, na prática, o docente não apenas transmite conhecimento, como também absorve as experiências e perspectivas trazidas pelos discentes.

Dessa maneira, a qualidade do ensino fica amplamente condicionada à qualidade do trabalho realizado pelo docente, no qual se pode observar que pensar, estudar e realizar a prática de docência são fundamentais nesse processo de qualificação profissional. Mais do que estabelecer a relação entre teoria e prática na docência universitária, o estágio docente permite a constatação de que ensinar exige comprometimento e a compreensão da docência como uma possibilidade de intervenção no mundo. Demanda a busca incessante pela diversidade de saberes fundamentais à qualificação técnica, que possibilita a autoridade necessária a cada professor, considerando que essa autoridade só terá validade quando articulada com a liberdade.

A revisão bibliográfica realizada a partir das reflexões realizadas na disciplina de Docência no Ensino Superior resultou no início da construção do perfil que desejamos para a atuação docente, pois trouxe para o debate temas fundamentais, como o fato de refletir sobre a docência a partir da identificação de quem é o sujeito que estamos formando. A disciplina, cujo propósito é qualificar para a docência universitária, fomentou o pensar a docência a partir dos processos de reflexão na ação, da busca pelo rigor metodológico para o desenvolvimento de uma função responsável e consciente da capacidade de transformação social que possui.

As reflexões sobre a relação entre teoria e prática na docência universitária foram, para mim, uma caminhada que está apenas no início e que terá que ter continuidade com comprometimento e dedicação, tendo em vista que pretendo ingressar na carreira acadêmica. A prática de sala de aula na graduação configurou-se um grande desafio, um momento de enriquecimento epistemológico e profissional. Uma prática permeada por conflitos, dúvidas e muitas expectativas, as quais só foram sanadas à medida que a experiência docente foi acontecendo e as atividades sendo realizadas com o auxílio da professora titular e dos docentes da disciplina de Docência no Ensino Superior, no mestrado. 
Acerca da docência universitária, resgato algumas palavras de Lauxen (2011), segundo a qual o profissional docente vai constituindo sua identidade a partir de sua história, de suas escolhas, de sua individualidade, formando-se e reformulando-se a partir de processos autorreflexivos que vão constituindo o "ser professor" a partir da significação social da profissão, revisando constantemente sua prática e suas tradições.

Trata-se de um processo complexo, uma vez que, conforme Lauxen (2011), envolve relações pessoais, projetos e processos que se produzem mutuamente, embasados numa visão de ser humano, educação e sociedade. As pessoas, nesse sentido, não nascem educadoras, mas se tornam educadoras quando se educam com o outro e com a realidade onde estão inseridas, num processo permanente de problematização, investigação, mediação e transformação do conhecimento mediante um projeto existencial e coletivo de construção humana.

\section{Referências}

BRASIL. Lei de Diretrizes e Bases da Educação Nacional. LDB. Lei n 9.394, de 20 de dezembro de 1996.

BRASIL. Ministério da Educação. Coordenação de Aperfeiçoamento de Pessoal de Nível Superior - CAPES. Plano Nacional de Pós-Graduação - PNPG 2011-2020. Brasília, DF, 2010(b). Disponível em: https://www.capes.gov.br/images/stories/download/PNPG. Acesso em: 28 out. 2019.

CONTRERAS, J. La Autonomía del Professorado. Preparação do texto Conceição Braga. Cortez: São Paulo, 2002.

ROSSATO, R. Século XXI: saberes em construção. Passo Fundo: UPF; 2002.

CUNHA, M. I. da. Trajetórias e lugares de formação da docência universitária: da perspectiva individual ao espaço institucional. Araraquara: Junqueira e Marins Editora, 2010.

CUNHA, M. I. da. Inovações Pedagógicas: o desafio da reconfiguração de saberes na docência universitária. In: PIMENTA, S. G.; ALMEIDA, M. I. de (org.). Pedagogia Universitária. São Paulo: Editora Universidade de São Paulo, 2009.

FREIRE, P. Pedagogia da Autonomia. Saberes necessários à prática educativa. 43. ed. São Paulo: Paz e Terra, 2011.

LAUXEN, S. de L. A docência na perspectiva interdisciplinar: desafios e possibilidades. In: SOUZA, A. E. de. (org.). Educação, sociedade e cultura: reflexões interdisciplinares. 1. ed. Curitiba, PR: CVR, 2011. 
PIMENTA, S. G. ANASTASIOU, L. G. C. Docência no Ensino Superior. São Paulo: Cortez, 2011.

SCHÖN, D. Educando o profissional reflexivo: um novo design para o ensino e a aprendizagem. Porto Alegre: Artmed, 2000.

SOARES, S. R. CUNHA, M. I. da. Programa de Pós-Graduação em Educação: lugar de Formação da Docência Universitária? Revista Brasileira de Pós-Graduação. Brasília, v.7, n. 14, p. 577-604, 2010.

STENHOUSE, L. Investigación y desarrollo del curriculum. Madrid: Morata, 1981.

UNIVERSIDADE DE CRUZ ALTA. Plano de Desenvolvimento Institucional - PDI 2018 2022. Disponível em: https://home.unicruz.edu.br/.

Enviado em: 29/07/2020

Aprovado em: 23/02/2021

Publicado em: 15/06/2021 